\title{
Participatory geographic information systems and public engagement within flood risk management
}

\author{
I. White, R. Kingston and A. Barker \\ School of Environment and Development, University of Manchester, Manchester, UK
}

\section{Correspondence \\ I. White, School of Environment and Development, University of Manchester, Manchester, UK \\ Email: lain.white@manchester.ac.uk}

DOI:10.1111/j.1753-318X.2010.01083.x

Key words

Flood risk management; stakeholder

engagement; participation; GIS; visualisation.

\begin{abstract}
In this paper we review the emerging lessons from a recent initiative on utilising Public Participatory Geographic Information Systems within Shoreline Management Planning to help unpack the theoretical and actual role of this approach for developing flood risk management policy options and scenarios. We discuss the benefits and limitations of stakeholder engagement in flood risk management decisions before highlighting some of the technical aspects of developing such an approach. We then examine how stakeholder access to mapping and spatial policies offers the potential for improved stakeholder dialogue and involvement in flood risk management. The paper highlights some of the underlying principles of the approach, potential pitfalls that the policy making community should avoid and good practice approaches to developing a participatory approach within flood risk management.
\end{abstract}

\section{Introduction}

Information and Communication Technologies (ICTs) have played an important role in spatial decision making since the 1950s when large scale computer models of urban and regional systems were first developed and implemented to support blue print planning. During the ensuing decades the use of computer technology to support spatial decision making was predominantly the domain of a technocentric, top-down, black-box paradigm. During 1970s and 1980s decision makers were increasingly moving towards more collaborative forms of policy making, which led to a divergence of the use of ICTs to support decision making within practice. During the 1990s the emergence of the Internet and the World Wide Web (Web) led to new methods of collaborative policy and decision making. The widespread adoption of desktop Geographic Information Systems (GIS), the spread of Web-based and interoperable GIS, Public Participatory GIS (PPGIS) and other digital, online, interactive planning and decision support systems has since offered further opportunities for more openly collaborative policy formulation. However, the use of tools such as these is still in their infancy, and there is real potential in utilising innovative engagement techniques in a whole host of policy arenas - including flood risk management. To this end, this article is designed to highlight a number of key issues in translating the theoretical benefits of online participatory approaches into practice.

\section{Flooding and stakeholder engagement}

Flooding is one of the most frequent natural hazards. The scale of the effects of flood events are usually quantified in climatic and economic terms, but increasing coverage of the victims of flooding and their long-term impacts in coping with the aftermath provide a much needed humanising element, better reflecting the view that: 'floods are an act of God, but flood losses are largely an act of man' (White, 1945). Since the advent of an interventionist approach to prevent flooding, the management of flood water has historically been placed within the remit of experts; from the drainage of the fens by Dutch engineers in the 17th century to the modelling and construction of the Thames Barrier (Halliday, 2004). In recent times however, the reliance on engineered defenses has been questioned as repeated severe flood events, increasing knowledge on the effects of climate change and a deeper understanding of the uncertain impacts of urbanisation has helped to expose the limitations of a predominately professionally orientated, technocratic approach. The wider realisation of the practical limitations in providing an effective defense against floods has helped to ushered in a new narrative in the UK that society needs to 'learn to live with rivers' and 'make space for water' (Institution of Civil Engineers, 2001; Department for Environment, Food and Rural Affairs [DEFRA] 2004). A belief also reflected in a number of other countries, such as the related 'room for the river' guidance released in the 
Netherlands (Ministry of Transport, Public Works and Water Management, 2006). This shift in approach heralded a gradual policy transition from engineered defense towards exploring natural and sustainable methods of management (White, 2008); a more realistic and pragmatic view, cognizant of the uncertainty inherent in flood risk.

Connected with this standpoint is the contemporary narrative that, as all risk cannot be either avoided or managed, citizens should accept more personal responsibility for their decisions on where to live. This view is a realistic position centered not on questioning the potential efficacy of techniques, or the expertise of engineers, rather acknowledging the rapidly evolving extent of knowledge and an appreciation of the nature of uncertainty. An inevitable consequence of this approach places increasing emphasis on professionals and institutions to adequately include communities in decision making processes. A key method to include people in policy formation and development choices is via spatial planning, which offers opportunities to engage people at a number of levels. Within this field a recent drive within the management of flood risk has been to reduce uncertainty by improving the volume and quality of data, assessing immediate and downstream risk, and using this knowledge to make more informed decisions. However, the implementation of development proposals, changes in land use, or the intricacies of schemes to provide hard defenses may subsequently receive stakeholder and public opposition, which can significantly reduce the speed of development.

Concomitant with this position is the view that if we expect people to accept more responsibility for their own exposure and vulnerability to risk they should be involved in decisions connected with flooding, such as is occurring within the field of water management as a whole. For example, in Europe the Water Framework Directive (EC, 2000) has placed considerable emphasis on public consultation and engagement in River Basin Management Plans. The policy has also helped to drive the participation agenda in member states, supported by complementary research initiatives, such as HarmoniCOP (HarmoniCOP, 2005). The participatory trend has also been reflected within recent flooding policy initiatives. In particular the EU Floods Directive specifically requires the involvement of a variety of agencies within decision making, including the public (EU, 2007).

While this knowledge based approach has undoubtedly helped reduce exposure to more readily quantifiable fluvial events, many recent flood episodes have been centered on inadequate sewerage and drainage systems, which are both difficult to predict and manage (Pitt, 2007). Existing information on areas that are at risk from small scale surface water inundation is difficult to compile and the recording of such events is inconsistent (Douglas et al., 2010), again providing weight to the argument that in practice many risks cannot be avoided or managed, as they are problematic to either foresee or quantify. Moreover, as flooding from these sources is forecasted to increase in future (Evans et al., 2004) the need to gather additional knowledge, effectively visualise and communicate uncertainty and further devolve decision making on risk to the general public becomes increasingly significant. Involving the public and wider stakeholders therefore can bring three considerable specific benefits to the field of flood risk management:

1. More personal responsibility;

2. Increased locally specific data; and

3. Wider endorsement of decisions.

The view that flood risk management should be based on good data, effectively assessed and weighted is not contradictory to the involvement of wider stakeholders. Research by White and Richards (2008) as to the level of local knowledge and its subsequent utilisation within spatial planning provided an insight into involving stakeholders in flood risk management. The study suggests that stakeholders and the community have a good awareness and understanding of flooding issues in their local area, especially if they have had experience of its effects. They appreciate that flooding may be mitigated by a variety of options beyond hard flood defenses and, significantly, they may possess detailed local knowledge of areas that are at risk from flooding and why this occurs.

Local knowledge of flood risk therefore can provide a valuable resource particularly in the event that data from any flood management agency or the water and sewerage provider is not available or out-of-date. Given the complexities of surface water management, stakeholder engagement therefore represents an opportunity to ensure that policies and land allocations utilise the best available information in relation to flood risk, particularly where the source of flooding is not an obvious one, such as a hidden watercourse or poor drainage. To take advantage of local knowledge should therefore not be seen as a public relations exercise, but as a means to increase the effectiveness and application of wider flood risk management decisions.

Both the spatial exposure to flooding, and the consequent institutional management responses, are not experienced in an equitable manner (Johnson et al., 2007). For example, flood events may strike certain geographical locations much more frequently than others and investment decisions on which new areas to protect may have been determined on a predominately economic basis, effectively disenfranchising smaller settlements. Involving stakeholders within flood risk management decision making provides a means of moving towards more fair proposals by widening the endorsing of policies and reducing public opposition, while also speeding up the development process. Therefore, engaging with a wider group of people not only increases the knowledge base relating to local flooding, but also helps to balance different 
social, economic and environmental needs from the perspective of the local community. Furthermore, the additional layer of accountability provides a valuable degree of transparency and links with the emerging agenda that the general public need to be more aware of the risks of flooding, the viability of responses and their own role in reducing community exposure and vulnerability.

There is clearly a certain amount of site-specific information to be gained from the local community. This sort of information can be considered an available resource, although its usefulness is limited by its predominant focus on sitespecific concerns, rather than shaping strategic responses. Nevertheless, it may provide a positive contribution to developing effective and accepted flood risk management policies, and increase the potential to manage areas affected by localised drainage problems, which frequently are not reported to the relevant authorities (Douglas et al., 2010). This longer term strategic approach to engagement should also be allied to a reactive proposal orientated approach, where the public are involved in specific decisions on flood management provision, such as whether to protect via hard defenses or managed realignment, and also strategies as to how they should be notified if the threat level is high.

In practice however the benefits of stakeholder involvement are difficult to be realised, as engaging people in decisions connected with flooding is haphazard, depending upon localised factors such as experience of recent flood events or the existence of motivated gatekeepers (Petts, 2007). In addition to a community willing to engage, there is also an onus on governance institutions to shift their emphasis from consultation to genuine participation. The timing of engagement can be a further issue, and for effective participation the start of the process is perceived to be better (Ledoux et al., 2005). Even when these circumstances are present White and Richards (2008) identify a number of barriers inhibiting meaningful public engagement in flood risk management:

1. Lack of interest or motivation;

2. Lack of knowledge of how to get involved;

3. Lack of understanding of how to apply policies in a reallife setting;

4. Lack of understanding of institutional and organisational responsibilities; and

5. Tendency to identify with more site-specific issues.

In summary, despite the emerging devolutionary shift of both water and risk management from the state to the individual, the implementation of this agenda may be problematic. In practice, it may be difficult to effectively engage lay people, while those who were motivated may be unsure about fundamental issues, such as who to contact and how to apply their knowledge. A key point is that traditional consultation procedures have been aimed at gaining agreement and acceptance of plans or proposals and not necessarily designed to either maximise response or gather local knowledge. Therefore current consultative engagement mechanisms operating within decision making processes may need re-examining if the benefits of wider stakeholder involvement within flood risk management are to be realised.

In order to more readily exploit data held by the community and widen their influence beyond reactive NIMBYism, a more innovative, proactive strategy should be employed. It is here that the potentially significant role of PPGIS could be usefully recognised and developed. As there is limited success in engagement with flood risk management policies via conventional consultative spatial planning processes, a more facilitative proactive approach could enable their knowledge to be more widely utilised and, importantly, translated into the policy arena. The following section explores the wider context of public participation and examines the use of GIS as an emerging technique for stakeholder engagement.

\section{New methods for stakeholder engagement}

Since the mid 1990s developments in ICTs has led to the development of a range of new and innovative methods to support public engagement in public policy decision making. This has recently included work to develop web-based PPGIS to facilitate engagement in spatial decision making in local, regional and national environmental planning issues (Kingston, 2002). Such systems allow the public and other stakeholders to engage in the decision and policy making environment through interactively interrogating geospatial data and associated attribute data. This has included the ability to examine policy related factors or physical features, and make informed judgements about proposals, scenarios or generating debate and discussion about place-based issues. These systems can range from digital Planning for Real ${ }^{\circledR}$ type methods to participatory appraisal through to multicriteria decision mapping (Kingston et al., 2000).

Public participation has become increasingly important in UK policy expressed through the Local Government Modernisation Agenda (LGMA) of the Labour Government since 1997. There is also an increased emphasis internationally on participation through the UN's Aarhus Convention (UNECE, 1998) which requires the public to have access to information and participation in decision making processes recognising that many of the environmental, social and economic challenges faced by societies across the globe cannot be tackled by public authorities in isolation but requires the active involvement of a range of stakeholders, including individual members of society. This is also supported by other international organisations including the World Bank (1996); OECD (2001) and the EC (2006). In connection with this, in the UK academics have observed a 
shift from government to governance in the public sector. The shift is linked to the LGMA and particularly to the engagement of citizens and stakeholders in a more horizontal process of governance as opposed to top-down governing (Phillips and Orsini, 2002; Rutherford, 2006; Raco et al., 2006). As part of their modernisation programme, the UK government has pledged to make services joined-up (also described as 'single-window', 'one-stop' or 'citizen-centric' approach to service delivery) and accountable, rejuvenate local democracy and engage citizens in local decisions to create 'strong and prosperous communities' (Department for Communities and Local Government [DCLG], 2006). The role of technology is central to the delivery of modern government from central to local:

Technology is one of the most important tools for transformation. It can improve the life chances of socially excluded people by increasing opportunities to intervene and tackle emerging problems

(DCLG, 2006, p. 139).

The potential of e-government for public participation has been captured in the central government rhetoric around LGMA. It is in this dynamic field where there is a cross-over between the Labour government's drive for 'transformational government - enabled by technology' (Cabinet Office, 2005) and its vision for local government set out in the Local Government White Paper 'Strong and prosperous communities' (DCLG, 2006). The emerging message for the direction of local government reform is that there is a fundamental need to engage citizens in local governance while the competitive global environment dictates that without transformation (enabled by technology) public services will not survive future economic pressures. Many local authorities look towards technological solutions to help streamline their business and support the inevitable process of change, thus pursuing the vision set out in the Transformational Government strategy.

It is argued here that e-government could help achieve the efficiency agenda and also support an active citizenry in a range of policy- and decision-making arenas. A question central to both strands of enquiry is how sustainable flood risk management might benefit from e-government. It should be first noted that a number of the five areas identified as barriers to meaningful engagement in flood risk management by White and Richards (2008) earlier in the paper, such as uncertainty on who to contact and how to get involved, could be potentially addressed via this methodology. It is also argued here that public participation is key to the delivery of more sustainable communities based on two assumptions: (1) that participation is desirable in a civil society; and (2) that PPGIS could be an efficient tool to facilitate this participation. This is taken with a realistic and pragmatic approach, hopefully without endorsing a utopian notion of information infrastructures as an inherently democratic transformation' rooted in technological determinism (Graham, 2004, p. 8). In summary, the on-line approach offers the following advantages:

- It is not time-limited in the same way as public meetings are, although they should be limited to a specified period to maintain community and organiser interest, and to fit with a planned schedule.

- It is not location limited so people can participate when they don't necessarily live in the immediate location.

- It provides access to groups that can not reach public participation meetings: the blind, deaf and those with mobility difficulties, etc.

- It allows for broader public involvement. Frequently public participation meetings are dominated by small, disproportionately vocal groups. Many individuals hesitate to express their concerns and opinions. The web allows increased potential anonymity between members of the public putting forward their views, and gives everyone involved a potential voice.

- Ease of data processing - the data inputted by the public can be tailored around processing needs, the information is already in electronic format, and it can often be displayed back to the public instantaneously in terms of a developing group consensus.

- Allows for an understanding of the public's understanding of a problem. Those who wish to provide information to the public can track what their pre-informed decisions are, how they alter, what paths they take through the provided and public-supplied knowledge, thus allowing such systems to be improved.

- It can encourage younger generations to participate who are more used to using this type of technology as the norm.

- It also offers more interactive approaches and instant responses to changes in scenarios or visual impacts.

Earlier a number of the barriers were identified in relation to inhibiting meaningful engagement in flood risk management. Table 1 shows how a PPGIS approach may be able to overcome some of these problems. The combination of visual tools, embedded information and accessibility could help raise participation within what has traditionally been a field dominated by experts. It is also important to recognise that this should be offered as a complimentary approach, not as a replacement to other methods.

Over the past 10 years a number of on-line PPGIS tools have been developed, tested and implemented at a range of spatial scales in support of real environmental decision making problems, providing a foundation to build upon when applying the methodology to flood risk management. More recent work has focused on engaging the public in regeneration of neighbourhoods by providing systems which allow people to complain about services or report 
Table 1 Overcoming the barriers to public engagement in FRM

\begin{tabular}{ll}
\hline Barrier & \\
\hline Lack of interest or motivation & $\begin{array}{l}\text { The use of GIS as a visualisation tool can be presented in a manner that aids understanding in a user } \\
\text { friendly way }\end{array}$ \\
$\begin{array}{l}\text { Lack of knowledge of institutional } \\
\text { responsibilities and how to get involved }\end{array}$ & $\begin{array}{l}\text { A wvell publicised website and dissemination strategy can help to explain the opportunities for } \\
\text { involvent outside of normal public meetings, etc. But one should not underestimate the importance }\end{array}$ \\
$\begin{array}{l}\text { Lack of understanding of how to } \\
\text { apply policies in a real-life setting and promotion of the site }\end{array}$ & $\begin{array}{l}\text { Again GIS can bring issues to life for the public when they can visualise the impact of flooding such as } \\
\text { the example: http://flood.firetree.net/ }\end{array}$ \\
$\begin{array}{l}\text { Tendency to identify with } \\
\text { more site-specific issues }\end{array}$ & $\begin{array}{l}\text { Our research has suggested that using GIS leads people to explore beyond their back-yard to include the } \\
\text { places where they work, study, shop and spend their leisure time }\end{array}$ \\
\hline
\end{tabular}

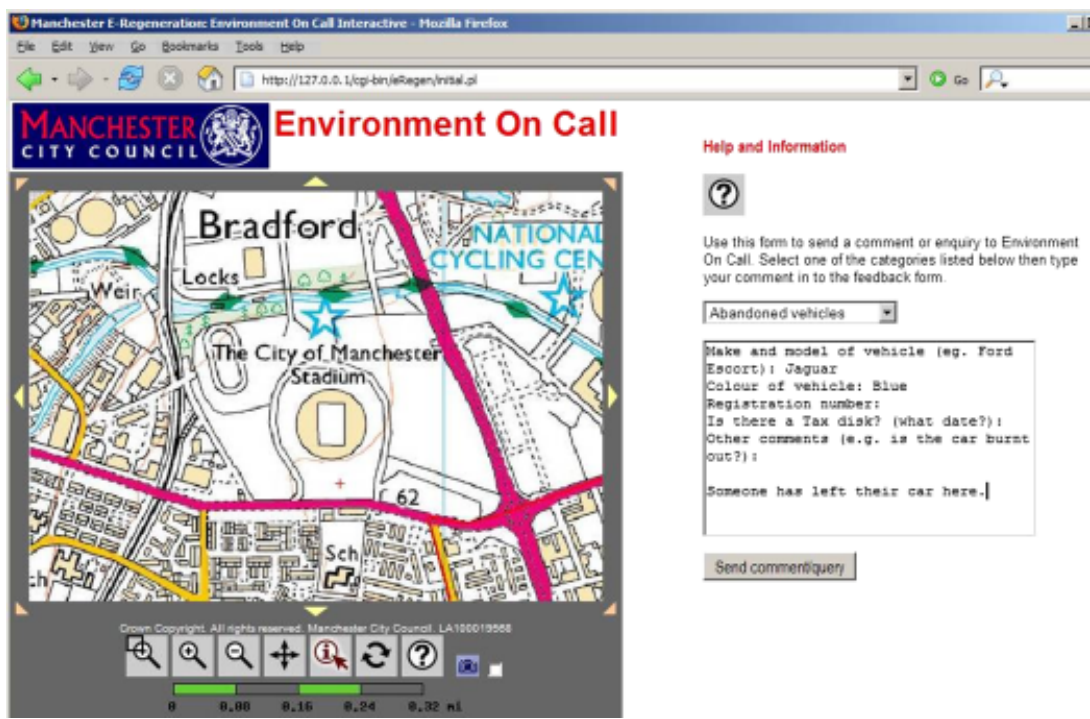

Figure 1 Public Participatory Geographic Information Systems (PPGIS) for reporting environmental issues.

problems in specific areas. This offers opportunities for the public to initiate discussions on issues of concern rather than being led by the Local Authority; reversing the usual model of the delivery of local services. As can be seen in Figure 1, a mapping interface allows users to pinpoint an exact location and make a comment about a specific service. The PPGIS records the $x, y$ coordinates together with a user profile and the comment they are making. This information is then stored in a central database for future analysis and relevant policy responses can be taken.

In the second example shown in Figure 2 a slightly more open-ended approach is adopted which integrates a threaded discussion list in to the PPGIS, essentially creating a georeferenced discussion. People can search spatially by topic, e.g. 'show me all discussions about coastal flooding' or users can generate their own discussion on a new topic, such as surface water flooding or green space provision. Further layers of spatial data can be added, such as spatial policy information, which users can interrogate and make comments on and link to the discussion list. It is then possible to analyse these responses at the end of the participatory process to bring together key themes and issues using textual analysis software, such as NVivo.

Alongside advances in the application of new and visual technology within a public participation process there are also a number of obstacles and issues, which should be considered from the outset. Previous research in this area indicates that application problems fall in to four areas: social access; map navigation and IT knowledge; domination of discussions by certain groups; and transparency and openness.

1. Social access - while Internet access continues to grow with nearly 15 million households in Great Britain (61\%) having Internet access in 2007 (84\% of those households had broadband) there are still many without access (National Statistics, 2007). As with all public participation process there is always difficulty in engaging certain hard to reach groups and the use of the Internet does not necessarily overcome this problem indeed it can exacerbate it. 


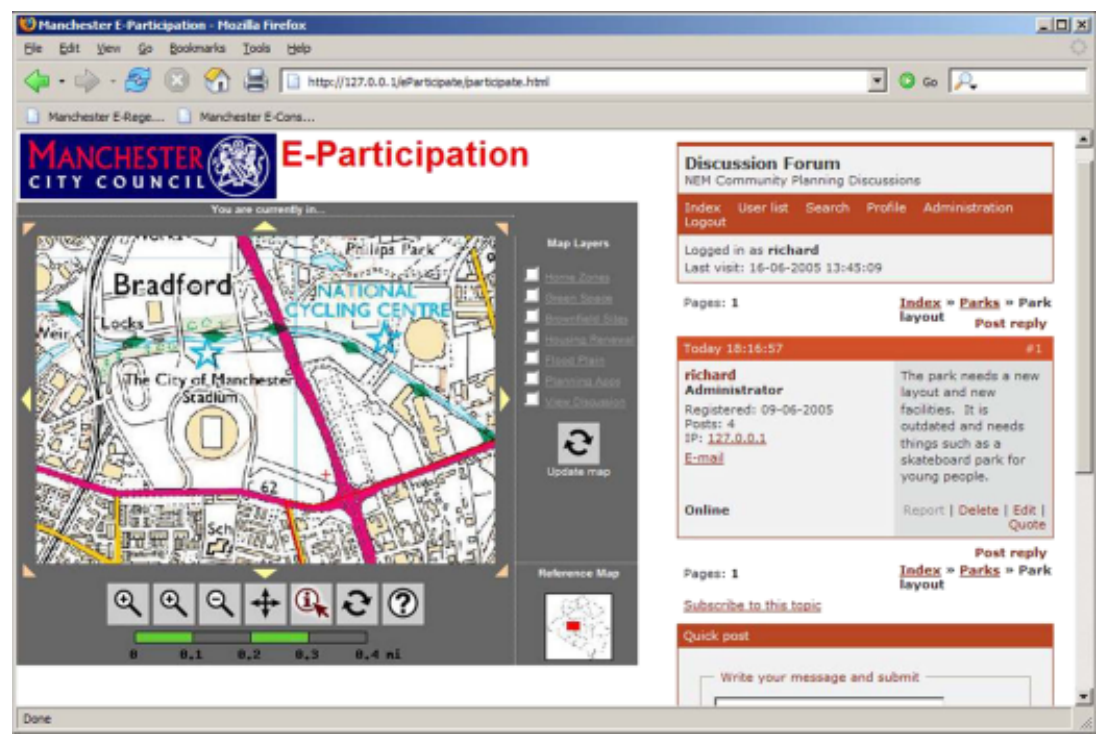

Figure 2 Public Participatory Geographic Information Systems (PPGIS) integrating geo-referenced threaded discussion list.

2. Map navigation and IT knowledge - there is an assumption that users can navigate a map, mouse and keyboard.

3. Domination of discussions by certain groups - as with any public participation process discussions can become dominated by certain groups or vocal individuals.

4. Transparency and openness - the use of a threaded discussion list will mean that all users of the system will be able to see other comments and discussions. It will be important that any decisions taken by professionals and institutions show how they have taken on board the discussions, comments and issues raised through the engagement process and how these link to policy and decision making.

Understanding both problems in engagement within flood risk management and with regard to participation more generally is therefore relevant when designing an approach to facilitate the effective inclusion. The following section describes the methodology utilised within a recent research project.

\section{Issues in developing a PPGIS framework}

In order review the potential of PPGIS as a means of improving stakeholder engagement within the public policy process, the authors were commissioned by the North West Coastal Group to establish a demonstration programme for e-governance within Shoreline Management Planning. The approach is centered around a web-based interface which draws on the latest geospatial technology to allow stakeholders to access, review and debate management pressures and alternative policy scenarios. Although focused on the north west of England the issues raised in this demonstra- tion project provide a useful basis for the consideration of approaches to stakeholder engagement within flood risk management in general.

In the light of the broadening participatory requirements of the Shoreline Management process, the project sought to review the potential of PPGIS provisions in meeting the policy requirements and to promote best participatory practice. To date, this is the first of such projects to have been undertaken for the Shoreline Management process and it provides a unique opportunity to explore the emerging role of ICT as a central component of devolved governance.

The project has been operationalised through the development of an interactive world wide web site, which has been developed in order:

- To stimulate interest with a view to facilitating communication and participation;

- To provide a forum for views, aspirations and debate;

- To provide a visual understanding of risk related pressures and potential responses; and

- To provide an environment for communication, empowerment and ownership.

Fundamental to the project was a recognition that the PPGIS development process would need to be developed in accordance with the phasing of the decision making process. On this basis, a hierarchy of development stages was established based on 'decision-making windows' contained with the policy cycle. This allowed the world wide web site to establish protocols for different forms of engagement and to enable different forms of technical facilitation to be pioneered. The nature of these stages and their associated ICT characteristics are outlined below. 


\section{Stage 1: Informing communities and collating local knowledge and attitudes}

The first phase of the process was geared towards the acquisition of baseline data with a view to determining to coastal functionality. Here it is important the data acquired relates not only to the processes of physical change which impact upon the shoreline, but also the socio-economic dynamics of the study area. In order to address both the extent and complexity of data required however, a number of participatory challenges needed to be overcome. As discussed earlier in the paper, traditional approaches to risk management have tended to prioritise formal expertise at the expense of input provided by the public. Furthermore, even in situations where public engagement has been actively sought, the public often lack either the awareness or motivation to become actively engaged (Petts, 2007; White and Richards, 2008).

Based on these concerns, the preliminary stage of the demonstration project contained two main components. The first attempted to improve public awareness of the policy process and to highlight significance of wider engagement. This required the development of a PPGIS platform which was able to not only acquire information, but to effectively communicate flooding and erosion issues. To do this, the website provided a series of thematic sections geared towards highlighting (a) the nature of the changing coastline, (b) the role of climate change and sea level rise, (c) the relevance of coastal change to local communities and (d) the role of engagement within the overall management process. The approach adopted is detailed in Figure 3.

The second component aimed to obtain baseline information from the wider public. To do this an online questionnaire survey was created which allowed participants to utilise threaded discussion lists based around thematic issues. The approach utilised open-source software and created an environment in which comments on focused issues could be created, submitted and discussed. The information sought related not only to the acquisition of scientific data, but also to perceptual and behavioural information. The initial stage of the approach therefore sought to both inform communities and collect local data.

\section{Stage 2: Spatial investigation and review}

The information generated in Stage 1 was used to establish and evaluate management issues and objectives for different localities. In this part of the process it was essential to generate a GIS framework to enable the public to review proposals within the context of their spatial application. As indicated previously, a major impediment to obtaining effective public feedback to flood risk management has been a tendency to detach proposals from their real-life setting. In response, the demonstration project established an on-line GIS using a customised Google Maps interface dynamically linked to a back-end database. The reasoning behind using Google Maps is threefold: it is 'free'; it is highly customisable; and probably most importantly from a users perspective, it is very simple to use and navigate (Hudson-Smith et al., 2007). Many proprietary on-line mapping systems make an assumption that the user has a certain degree of GIS knowledge and an understanding of relevant terminology when, most likely, they do not (Kingston et al., 2000). Considering the public audience that will be making use of such a tool, it was important to create a website which was both intuitive and simple to use. Therefore, a fairly basic geospatial interface was established which allows users to query issues and options for different coastal subcells and post georeferenced comments at user-defined locations within a

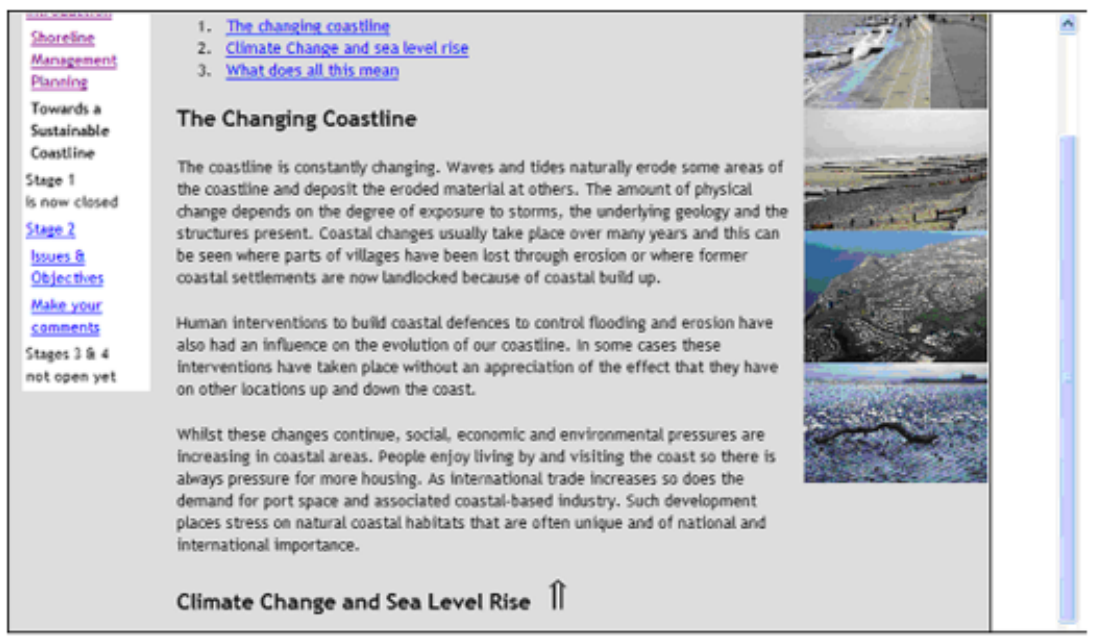

Figure 3 Using Public Participatory Geographic Information Systems (PPGIS) to facilitate awareness and engagement. 


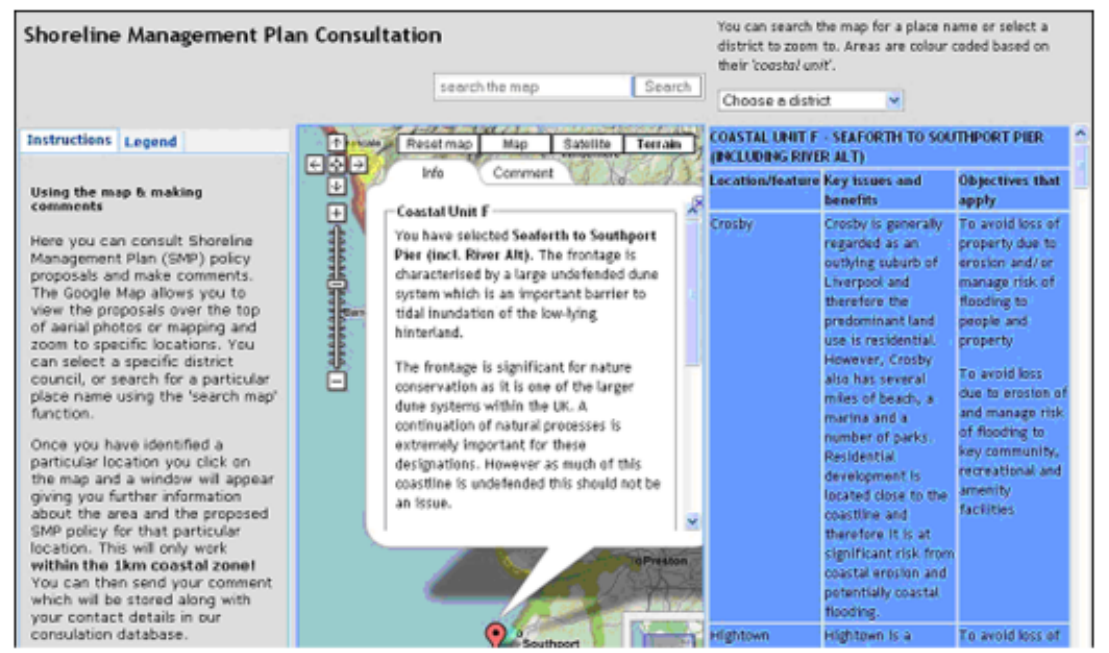

Figure 4 Using Public Participatory Geographic Information Systems (PPGIS) to evaluate management options by spatial location.

$3 \mathrm{~km}$ inland and sea-ward coastal buffer zone (Figure 4). These comments are then fed back in to the process in a similar manner to other consultation media, enabling both local data to inform the process and educating users on managerial issues and objectives.

\section{Stage 3: The visual evaluation of policy}

The final phase of the demonstration project is designed to develop visualisations of various policy scenarios. By providing interactive access to elements of the proposed SMP plan, users can obtain information (by turning layers of data on/off), formulate opinions (by reading attribute information about data/policy) and make informed judgements on proposals. This has the potential to go far beyond more standard methods of consultation, which tend to focus just on dissemination and the receipt of static information. The approach emphasises the main policy options available: (1) holding the existing defensive line, (2) advance the existing defense line, (3) managed realignment and (4) no active intervention. By incorporating these scenarios within the PPGIS, users were able to develop a more sophisticated understanding of the relationship between place and risk. This stage of the project will store all responses in a georeferenced database. This information can be disseminated for review later in the process by stakeholders and allows the possibility of viewing other comments and developing an understanding of competing viewpoints. Updated policies can be displayed within the system as policy proposals and decisions are finalised.

Through a three stage process the research attempted to address some of the more common problems inhibiting effective participation within an intuitive online tool. While the design of the approach did allow for a more facilitative and inclusionary strategy, the next section discusses how the benefits of higher participation may still be difficult to achieve in practice.

\section{Discussion and conclusion}

E-participation can be viewed as an elitist technology requiring a degree of skill to make use of it and can therefore exclude certain people from the participatory process. It is important therefore that this is not the only approach taken but as part of a suite of methods. What the PPGIS technology does offer though is a means by which users can engage more interactively in the process. The Google Map interface allows aerial photos as well as a standard mapping interface to be used. A user can also type in a place name, street address or postcode to identify particular locations. Further, it is possible to provide a list of locations that a user can select and then zoom into. There are issues that the organisation developing such an approach needs to consider with a number of complications in relation to the ownership and accuracy of the data being presented. Who owns the data and who controls it can have impacts on the outcomes of the decision making process within a GIS environment. A good example here is in wind farm siting where there are numerous examples of PPGIS (Berry et al., 2007). GIS for wind farm siting often utilises contour data to generate $3 \mathrm{D}$ surfaces but the algorithms within the GIS for converting contour data in to 3D surfaces will produce different outputs depending upon the contour intervals initially used. This offers differing degrees of accuracy when undertaking viewshed analysis in relation to the visual impact of a wind farm. Other complications can arise over data when there are disputes over its veracity - has it come from an independent source or is it tainted in some way by one 
organisation or another? These are problems which are influencing on-going and future research in this field.

In a previous section we highlighted four issues of which three could equally apply to any on-line consultation exercise: social access; domination of the discussion; and transparency and openness. What we have learned from testing the SMP PPGIS tool is that providing access to PPGIS at public meetings is one way of overcoming the problem of social access. It is also important to advertising the website in relevant local publications such as newspapers and a dedicated person responsible for publicity certainly helped. The domination of the discussion by particular groups did not arise in the this particular case but it is possible to address this issue through the monitoring of IP addresses to highlight multiple hits from one or a group of IP address ranges. The moderation of any discussion forum may still need to be undertaken however and in some ways is not dissimilar to more conventional approaches of participation. The use of a threaded discussion linked to the map was not tested but would be one way to more easily moderate a policy debate. It also provided an audit trail of how stakeholders were consulted, what was said and how issues raised were responded to. At a time when the public sector is required to be more cost effective, accountable and transparent in its decision making the use of these map based tools offers them a fully accountable, georeferenced record of the discussions which have taken place around a particular decision making problem. The data that the tool generated in the form of georeferenced discussions can be analysed off-line once a consultation has been completed much quicker than in more traditional approaches as all the responses are already in an electronic $\mathrm{xml}$ format.

The historical remit of flood risk as being exclusively within the realm of the expert is being increasingly challenged as repeated flood events and a greater understanding of uncertainty contribute towards a fuller comprehension of limitations in flood risk management provision. The Pitt (2007) Review identifies this process as moving from a 'need to know' towards a 'need to share' culture - in essence professionals being more open and honest about communicating flood risk and the ability to manage it effectively to citizens. A key policy narrative across many countries is therefore to devolve a degree of responsibility away from a top down institutional accountability towards a partnership approach, where people increasingly take personal responsibility for limiting their own exposure and vulnerability to flooding. To realise this ambition the public needs to have access to higher levels of information, understand key messages and contribute towards the construction of accepted policy responses. Communicating this multifaceted data is key however, and effectively translating complex policy documents into a simple and coherent message aimed at lay people can be greatly enhanced by embedding policy options within visualisation techniques.

The approach to addressing modern flood risk is centered on gathering suitable knowledge and then applying this within a risk based approach to develop the best combination of protection and value for money. Incorporating the public within this methodology is clearly beneficial as stakeholders are becoming increasingly educated on localised flood risk management sources and receptors. Although engagement with stakeholders can bring benefits to the field of flood risk management, research has shown that traditional methods are an imperfect tool for this task and the public still experience fundamental problems, such as who to contact, how to do so and what information would be useful. The process of engagement therefore needs to be made easier and the findings managed better to realise these advantages.

More innovative and proactive methods could address issues associated with facilitating stakeholder access and moving away from a deliberative consultative approach towards a more active facilitative process; in effect mirroring the processes utilised within research such as this. The focus here is also on negotiation and dialogue, demonstrating how information has influenced and complemented expert knowledge; with professionals interpreting and translating lay opinion into policy formation. The use of PPGIS offers real potential in this arena, in particular by combining the spatial nature of flood risk with specific questions highlighting options for policy responses within an accessible visual format. Although the research has been conducted within a UK environment, the context of the problem is transferable across national boundaries, as is the utilisation of on-line, collaborative decision support tools, such as PPGIS.

In addressing flood risk via visualisation tools we need to be careful however, and recognise that although technology can solve some problems it can also create new difficulties. The progression of engagement into the multimedia sphere runs the risk of replacing barriers such as 'how to contribute' with a similar but equally socially constructed issue connected with 'access to technology'. An effective managerial approach therefore will have to incorporate PPGIS and other visual approaches within an appropriate suite of methods, aiming where possible to offset weaknesses and maximise useable responses from stakeholders. It is also clear that education regarding the application and utility of these tools is equally a requirement for the expert, as engagement holds no purpose without a clear and demonstrable route into policy and practice. Finally it is important that when citizens are engaged in such participatory processes, the politicians and wider policy making community listen to what the community is telling them and act upon it in a way that meets the needs of all those involved. If the technology does not lead to more collaborative, effective and accepted decisions then although we may be addressing some barriers we are also creating others. 


\section{References}

Berry R., Higgs G., Kidner D. \& Langford M. Examining the potential of internet-based geographical information systems for promoting public participation in wind farm planning in the UK. Proceedings of GISRUK NUI Maynooth, Ireland, 11-13 April 2007.

Cabinet Office. Transformational Government - enabled by technology. Norwich, TSO, 2005.

Department for Communities and Local Government (DCLG). Strong and prosperous communities - the Local Government White Paper, 2006. Available at http://www.communities.gov. uk/strongprosperouscommunitieswp (accessed 12 March 2009).

DEFRA. Making space for water: developing a new government strategy for flood and coastal erosion risk management in England. London: DEFRA, 2004.

Douglas I., Garvin S., Lawson N., Richards J., Tippett J. \& White I. Urban pluvial flooding: a qualitative case study of cause effect and non-structural mitigation. J Flood Risk Manage 2010, 3, (2), 112-125.

European Commission. Summary report on the inventory of $E U$ Member States' measures on access to justice in environmental matters. Belgium: Milieu Ltd, 2006.

European Commission. Water framework directive, 2000. Available at http://eur-lex.europa.eu/LexUriServ/LexUriServ. do?uri=CELEX:32000L0060:EN:HTML (accessed 15 September 2009).

European Union. On the assessment and management of flood risks, 2007. Available at http://eur-lex.europa.eu/LexUriServ/ site/en/oj/2007/1_288/1_28820071106en00270034.pdf (accessed 15 September 2009).

Evans E., Ashley R., Hall J., Penning-Rowsell E., Saul A., Sayers P., Thorne C. \& Watkinson A. Foresight. Future flooding. Scientific summary: volume 1 - future risks and their drivers. London: Office of Science and Technology, 2004.

Graham S. ed. The cybercities reader. London: Routledge, 2004.

Halliday S. Water: a turbulent history. Stroud: Sutton Publishing, 2004.

Harmonicop. Learning together to manage together: improving participation in water management, 2005. Available at http:// www.harmonicop.uos.de/HarmoniCOPHandbook.pdf (accessed 15 September 2009).

Hudson-Smith A., Milton R., Batty M., Gibin M., Longley P. \& Singleton A. Public domain GIS, mapping \& imaging using web-based services. CASA Working Paper 120, Centre for Advanced Spatial Analysis, London, 2007.

Institution Of Civil Engineers. Learning to live with rivers. London: Institution of Civil Engineers, 2001.

Johnson C., Penning-Rowsell E. \& Parker D. Natural and imposed injustices: the challenges in implementing 'fair' flood risk management policy in England. Geographic J 2007, 173, (4), $374-390$.
Kingston R. Web based PPGIS in the UK. In: W. Craig, ed. Community empowerment, public participation and geographic information science. London: Taylor \& Francis, 2002, 101-112.

Kingston R., Carver S., Evans A. \& Turton I. Web-based public participation geographical information systems: an aid to local environmental decision-making. Computers, Environ Urban Syst 2000, 24, (2), 109-125.

Ledoux L., Cornell S., O’Riordan T., Harvey R. \& Banyard L. Towards sustainable flood and coastal management: identifying drivers of, and obstacles to, managed realignment. Land Use Policy 2005, 22, (2), 129-144.

Ministry of Transport, Public Works and Water Management. Spatial planning key decision 'Room for the River', 2006. Available at http://www.ruimtevoorderivier.nl/files/Files/ brochures/EMAB\%20PBK\%20Engels.pdf (accessed 1 July 2009).

National Statistics. Internet access 2007: households and individuals. London: HMSO, 2007.

OECD. Citizens as partners: information, consultation and public participation in policy-making. Paris: OECD, 2001.

Petts J. Learning about learning: lessons from public engagement and deliberation on urban river restoration. Geographic J 2007, 173, (12), 300-311.

Phillips S. \& Orsini M.Mapping the links: citizen involvement in policy processes. Canadian Policy Research Networks, 2002. Available at http://www.cprn.org/ (accessed 10 March 2009).

Pitt M. Learning lessons from the 2007 floods, an independent review by Sir Michael Pitt. London: Cabinet Office, 2007.

Raco M., Parker G. \& Doak J. Reshaping places of local governance? Community strategies and the modernisation of local government in England. Environ Plann C 2006, 24, 475-496.

Rutherford T. Local representations in crisis: governance, citizenship regimes, and UK TECs and Ontario local boards. Environ Plann D 2006, 24, 409-426.

UNECE. Convention on access to information, public participation in decision-making and access to justice in environmental matters. Geneve: UNECE, 1998.

White G.F. Human adjustment to floods. Research Paper No. 29, Department of Geography, University of Chicago, Chicago, 1945.

White I. The absorbent city: urban form and flood risk management. Proceedings of the Institution of Civil Engineers: Urban Design and Planning, December (DP4), 2008, 151-161.

White I. \& Richards J. Stakeholder and community engagement in flood risk management and the role of AAPs. Flood Risk Management Research Consortium Report, University of Manchester, Manchester, 2008.

World Bank. Participation source book. Washington DC: The International Bank for Reconstruction and Development/The World Bank, 1996. 